Revue bibliographique pour le domaine irano-aryen

\title{
Richard Gordon. « Persae in spelaeis solem colunt: Mithra(s) between Persia and Rome »
}

\section{Olivia Ramble}

\section{(2) OpenEdition \\ 1 Journals}

\section{Édition électronique}

URL : http://journals.openedition.org/abstractairanica/50974

DOI : 10.4000/abstractairanica.50974

ISBN : 1961-960X

ISSN : 1961-960X

Éditeur :

CNRS (UMR 7528 Mondes iraniens et indiens), Éditions de l'IFRI

\section{Référence électronique}

Olivia Ramble, «Richard Gordon. «Persae in spelaeis solem colunt: Mithra(s) between Persia and Rome » ", Abstracta Iranica [En ligne], Volume 40-41 | 2019, document 24, mis en ligne le 30 décembre 2019, consulté le 20 avril 2021. URL : http://journals.openedition.org/abstractairanica/50974 ; DOI https://doi.org/10.4000/abstractairanica.50974

Ce document a été généré automatiquement le 20 avril 2021.

Tous droits réservés 


\title{
Richard Gordon. « Persae in spelaeis solem colunt: Mithra(s) between Persia and Rome »
}

\author{
Olivia Ramble
}

\section{RÉFÉRENCE}

Richard Gordon. « Persae in spelaeis solem colunt: Mithra(s) between Persia and Rome » in Rolf Strootman, Miguel John Versluys (eds.). Persianism in Antiquity. Stuttgart: Franz Steiner, 2017, p. 289-325 (Oriens et Occidens 25)

1 L'A. applique le concept de "persianisme ", thème auquel est dédié l'ouvrage collectif, à la question controversée d'une possible continuité entre le culte de Mithra à Rome et celui voué 400 ans plus tôt à une divinité quasi homonyme en Iran achéménide. Cette approche lui permet de se défaire du débat binaire axé sur l'origine - romaine ou iranienne - du Mithra romain et d'étudier l'émergence et la diffusion de son culte dans la Méditerranée plutôt comme un phénomène de «réappropriation» religieuse. L'A. nous invite notamment à nous interroger sur les acteurs de ce processus et propose un modèle basé sur l'initiative individuelle des mystagogues. Ceux-ci se seraient inspirés d'une tradition existante, incarnée architecturalement par le mithraeum et iconographiquement par la figure de Mithra-elle-même construite sur des topoi grecs concernant le 'Perse' comme son habit 'oriental' ou encore sa maîtrise du tir à l'arcainsi que le motif de la tauroctonie. Mais l'attrait de la « Heilsgüter » qu'ils professaient dépendait structurellement des innovations convaincantes que fournissait notamment la notion féconde d'une origine orientale de Mithra. 


\section{AUTEURS}

OLIVIA RAMBLE

Doctorante EPHE, Mondes iranien et indien, Paris 